Org Lett. 2015 December 4; 17(23): 5858-5861. doi:10.1021/acs.orglett.5b03034.

\title{
A Highly Stereoselective, Efficient, and Scalable Synthesis of the C(1)-C(9) Fragment of the Epothilones
}

\author{
Corinne N. Foley and James L. Leighton ${ }^{\star}$ \\ Department of Chemistry, Columbia University, 3000 Broadway, Mail Code 3117, New York, NY \\ 10027
}

\begin{abstract}
A second-generation synthesis of the $\mathrm{C}(1)-\mathrm{C}(9)$ fragment of the epothilones is reported. The key tandem intramolecular silylformylation/crotylsilylation/"aprotic" Tamao oxidation sequence has been redeveloped as a stepwise intermolecular variant, allowing excellent levels of diastereoselectivity in the crotylation step, and proceeds in $50 \%$ overall yield on gram scale. An improved synthesis of the homopropargyl alcohol starting material is also described, which proceeds in 4 steps and $>99 \%$ ee from inexpensive starting materials and is amenable to multigram scales.
\end{abstract}

\section{Graphical abstract}

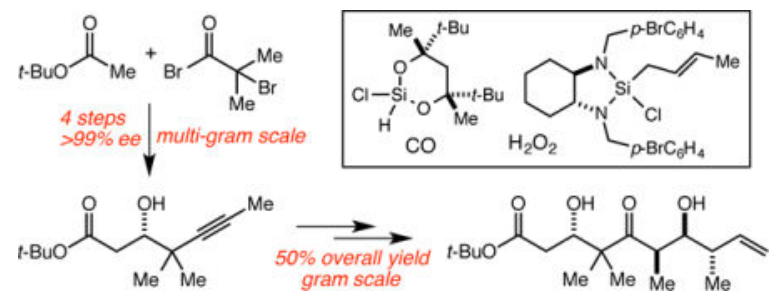

\begin{abstract}
The epothilone family of natural products (Figure 1) ranks as among the most important and promising of the large collection of microtubule-stabilizing agents (MSAs) known to express their anti-mitotic activity by binding to the taxane binding site on the interior of microtubules. ${ }^{1}$ Epothilone B (epo B) in particular possesses sub-nanomolar potencies against a variety of cell lines, and in 2007 the FDA approved ixabepilone (the lactam analog of epo B) for use in the treatment of particularly aggressive and otherwise unresponsive forms of metastatic breast cancer. ${ }^{2}$ Extensive SAR studies have been carried out in numerous laboratories, ${ }^{3}$ and this has led to several analogs being advanced into clinical trials, most notably sagopilone, ${ }^{4}$ whose development has been halted for unspecified reasons despite demonstrating efficacy in several Phase II trials, and iso-fludelone, ${ }^{5}$ Danishefsky's
\end{abstract}

\footnotetext{
*Corresponding Author:leighton@ chem.columbia.edu.

Supporting Information

Experimental details, spectroscopic and analytical data for all new compounds. This material is available free of charge via the Internet at http://pubs.acs.org.

Notes

The authors declare no competing financial interest.
} 
designed analog that has exhibited a remarkably favorable pharmacokinetic profile in an extensive pre-clinical evaluation and that is currently being evaluated in a Phase I trial. As a prelude to launching our own program in the design, synthesis, and evaluation of epothilone analogs possessing novel functionality, we targeted the development of an efficient, stepeconomical, and scalable synthesis ${ }^{6,7}$ of the $C(1)-C(9)$ fragment that is conserved in every important epothilone derivative save sagopilone.

In our broader program dedicated to the synthesis and evaluation of novel analogs of bioactive polyketide natural products, we have emphasized the development of stepeconomical and practical and scalable syntheses as it is only this combination that can facilitate the analog work in a truly time- and resource-efficient manner. To that end, we recently reported a synthesis of the $\mathrm{C}(1)-\mathrm{C}(9)$ fragment of the epothilones using an application of the one-pot tandem alkyne silylformylation/crotylsilylation and Tamao oxidation/diastereoselective tautomerization reaction sequence ${ }^{8}$ to set the $\mathrm{C}(6), \mathrm{C}(7)$, and $\mathrm{C}(8)$ stereocenters in a highly step-economical and gram-scalable way ( $\mathbf{2}$ to $\mathbf{3}$, Figure 2 ). ${ }^{9}$ The key methodological innovation developed for that purpose was a set of "aprotic" Tamao oxidation conditions that resulted in a highly (14:1) syn-diastereoselective tautomerization step to set the $\mathrm{C}(6)$ stereocenter. As excited as we were by the remarkable transformation of $\mathbf{2}$ to $\mathbf{3}$, we felt that other aspects of the route (e.g. the synthesis of $\mathbf{1}$ and the moderate 1,5diastereoselectivity of the intramolecular crotylation event) might put limits on the ease with which we could move multi-gram quantities through the sequence in a time- and resourceefficient manner. We therefore targeted the development of a second-generation synthesis of 1 with significantly improved step-economy, scalability, and enantioselectivity, as well as a modified version of the silylformylation/crotylation/oxidation sequence that would proceed with improved diastereoselectivity in the crotylation event and improved overall efficiency.

Our first task was the development of a synthesis of $\mathbf{1}$ that proceeds in fewer, yet more easily scaled steps, and that delivers the target with significantly improved enantiomeric purity. The second-generation synthesis of homopropargyl alcohol $\mathbf{1}$ that we devised to achieve these goals begins with a Claisen condensation between $t$-butyl acetate and $\alpha$ bromoisobutyryl bromide (both commercially available and inexpensive) to give $\beta$-ketoester 4 in 55\% yield on multi-gram scales. Noyori hydrogenation ${ }^{10}$ of $\mathbf{4}$ proceeds with exceptional efficiency and enantioselectivity to give $\mathbf{5}$, which is, without chromatographic purification, treated with $\mathrm{Na}_{2} \mathrm{CO}_{3}$ to effect the formation of epoxide 6 . This latter reaction required some optimization, as the epoxide, once formed, is susceptible to enolization and elimination. Once optimized, this two-step procedure reliably produced $\mathbf{6}$ in excellent overall yield (88\%) and in $>99 \%$ ee on multi-gram scales. Finally, the epoxide opening reaction with propyne according to the Pagenkopf method ${ }^{11}$ that we used previously delivers the target homopropargyl alcohol 1 in $60 \%$ yield. This four-step procedure is amenable to multi-gram scales ( $6.5 \mathrm{~g}$ of $\mathbf{1}$ was produced in one run through the sequence), produces $\mathbf{1}$ essentially enantiomerically pure, and employs only inexpensive starting materials and reagents.

Our proposed solution to the moderate 1,5-diastereoselectivity of the crotylation step in the reaction sequence described in Figure 2 was to simply perform it as an intermolecular externally-controlled reaction following silylformylation with a diphenylsilyl group in place of the di-cis-crotylsilyl group. ${ }^{12}$ Indeed, we had every reason to expect that this would be a 
straightforward solution based on our previous demonstration of the efficient and highly enantioselective $\mathrm{Sc}(\mathrm{OTf})_{3}$-catalyzed crotylation of $\mathbf{7}$ with trans-crotylsilane $\mathbf{8}$ to give $\mathbf{9}$, while the subsequent transformation of $\mathbf{9}$ to $\mathbf{1 0}$ using the "standard" anti-diastereoselective Tamao oxidation/tautomerization conditions established that a structure of this type was a viable oxidation substrate (Scheme 2). ${ }^{13}$ Thus, silylation of ent-1 (the exploratory reactions we conducted to test this idea were carried out prior to the development of the chemistry described in Scheme 1 using a sample of ent-1 that was prepared in $78 \%$ ee) with diphenylchlorosilane provided $\mathbf{1 1}$ in $95 \%$ yield, and $\mathrm{Rh}(\mathrm{I})$-catalyzed silylformylation ${ }^{14}$ then produced aldehyde $\mathbf{1 2}$ in $92 \%$ yield. As expected, $\mathrm{Sc}(\mathrm{OTf})_{3}$-catalyzed crotylation ${ }^{13}$ of $\mathbf{1 2}$ with silane $8^{15}$ proceeded highly diastereoselectively to give $\mathbf{1 3}$ in $67 \%$ yield (after chromatographic separation of the minor diastereomer that resulted from crotylation of the small amount of ent-12). Unfortunately, our satisfaction was short-lived as subjection of $\mathbf{1 3}$ to the aprotic Tamao oxidation conditions unexpectedly produced only trace amounts of any oxidation products. Even more surprisingly given the success of the transformation of 9 to 10, the standard Tamao oxidation conditions also failed to produce any meaningful amounts of oxidation products. This result seemed to implicate the $t$-butyl ester as playing a key role in the inertness of $\mathbf{1 3}$ to either set of oxidation conditions, as the presence or absence of the ester appears to be the only significant difference between substrates $\mathbf{9}$ and $\mathbf{1 3}$. Based on this analysis, we speculate that at least under the conditions of the oxidation reactions, $\mathbf{1 3}$ may exist as hexa-coordinate silane $\mathbf{1 4}$ thereby preventing fluoride displacement of the alkoxide, the presumed prerequisite for the oxidation step to occur, and note that Hoveyda advanced a related hypothesis to explain the recalcitrance of a $\beta$-hydroxy siloxane to undergo protodesilylation with $n$-Bu $\mathrm{BF}_{4}{ }^{16}$

Regardless of the mechanistic basis for the surprising inertness of $\mathbf{1 3}$ to Tamao-type oxidation, we decided to examine whether we could achieve greater electronic activation of the silane by replacement of the phenyl groups with alkoxy groups. While we were hopeful that this would allow for a productive oxidation notwithstanding our speculation regarding hexa-coordinate silane 14, we were also concerned about the hydrolytic stability of alkoxy silanes, which would have to survive the silylformylation/crotylation sequence and more specifically the workup and isolation procedures following the crotylation step. A series of dialkoxychlorosilanes with varying degrees of steric hindrance (15a-d) were prepared and used to silylate alcohol 1 (Scheme 3). As feared, the hydrolytic instability of silanes 15a-c made handling of the intermediates 16a-c and 17a-c difficult, and more importantly rendered the isolation of crotylation products 18a-c impracticable in anything greater than trace amounts. This led us to use the significantly more hindered dialkoxysilane 15d, which had the desired effect of imparting hydrolytic stability to the intermediates in the sequence and allowed for the isolation of $\mathbf{1 8 d}$ in $49 \%$ overall yield from $\mathbf{1}$. Gratifyingly, $\mathbf{1 8 d}$ proved to be a viable substrate for the aprotic Tamao oxidation using the previously developed conditions, giving 3 in $72 \%$ yield and with 11:1 diastereoselectivity at C(6). It is not entirely clear that this result is consistent with our hypothesis regarding the inertness of diphenylsilane 13, but we note that it is possible that the steric hinderance of dialkoxysilane 18d might destabilize the hexa-coordinate silane corresponding to 14. Regardless, the successful transformation of $\mathbf{1 6 d}$ to $\mathbf{3}$ constituted an encouraging proof-of-concept result. 
Final optimization of the conversion of $\mathbf{1}$ to $\mathbf{3}$ focused on even more sterically hindered dialkoxysilanes, and to that end silane 15e was prepared as an inconsequential 1:1 mixture of diastereomers (Scheme 4). The silylformylation/crotylation sequence was then repeated using silane 15e, and we were delighted to find that it proved efficient, robust, and scalable as 18e was isolated in $70 \%$ overall yield from 1 on a gram scale $(\mathbf{1 6 e}, \mathbf{1 7 e}$, and $18 \mathbf{e}$ were all produced as an inconsequential 1.6:1 mixture of diastereomers at silicon). Unfortunately, our satisfaction was once again short-lived as the steric hindrance that rendered this sequence so efficient and practicable now rendered the aprotic Tamao oxidation sluggish and inefficient. We wondered whether this problem could be addressed with a higher concentration of the active oxidant, and noted that in his original report Tamao had shown that 2,3-dimethylhydroquinone reacted with $\mathrm{O}_{2}$ to generate $\mathrm{H}_{2} \mathrm{O}_{2}$ at a faster rate than did methylhydroquinone. ${ }^{17}$ Indeed, we were gratified to find that this modification to the aprotic Tamao oxidation conditions restored the lost reactivity ${ }^{18}$ and led to the conversion of $\mathbf{1 8 e}$ to 3 in 71\% yield as a 9:1 mixture of diastereomers at $C(6)$. Treatment of $\mathbf{3}$ with triethylsilyl triflate (TESOTf) completed the synthesis of the fully elaborated $\mathrm{C}(1)-\mathrm{C}(9)$ fragment and gave acid $\mathbf{1 9}$ in $85 \%$ yield.

We have devised a second-generation synthesis of the $\mathrm{C}(1)-\mathrm{C}(9)$ fragment of the epothilone family of natural products with significantly improved step-economy, stereoselectivity, robustness, and scalability. Along the way, we encountered an unexpected failure of the previously developed and syn-selective aprotic Tamao oxidation/tautomerization conditions, and devised a more highly activated hydrosilane that was both compatible with the silylformylation/crotylation sequence and that also allowed for a successful and diastereoselective application of the aprotic Tamao oxidation/tautomerization reaction. The synthesis begins with $t$-butyl acetate and a-bromoisobutyryl bromide, and proceeds in $12 \%$ overall yield to completed fragment $\mathbf{1 9}$ by way of a nine step/eight pot sequence that is experimentally simple and robust, proceeds with high levels of diastereo- and enantioselectivity, and is amenable to being carried out on gram/multi-gram scales. Importantly, the practicality and scalability of the route allow the rapid stockpiling of intermediates, and it is our expectation that this will greatly facilitate the synthesis and exploration of novel and functional epothilone analogs.

\section{Supplementary Material}

Refer to Web version on PubMed Central for supplementary material.

\section{Acknowledgments}

Research reported in this publication was supported by the National Institute of General Medical Sciences of the National Institutes of Health under Award Number R01GM058133. The content is solely the responsibility of the authors and does not necessarily represent the official views of the National Institutes of Health.

\section{References}

1. (a) Bollag D, McQueney P, Zhu J, Hensens O, Koupal L, Liesch J, Goetz M, Lazarides E, Woods CM. Cancer Res. 1995; 55:2325-2333. [PubMed: 7757983] (b) Gerth K, Bedorf N, Höfle G, Irschik H, Reichenbach H. J Antibiot. 1996; 49:560-563. [PubMed: 8698639] (c) Höfle G, Bedorf N, Steinmetz H, Schomburg D, Gerth K, Reichenbach H. Angew Chem Int Ed. 1996; 35:1567-1569. 
2. (a) Lee FYF, Borzilleri R, Fairchild CR, Kim SH, Long BH, Reventos-Suarez C, Vite GD, Rose WC, Kramer RA. Clin Cancer Res. 2001; 7:1429-1437. [PubMed: 11350914] (b) Lee FYF, Borzilleri R, Fairchild CR, Kamath A, Smykla R, Kramer R, Vite G. Cancer Chemother Pharmacol. 2008; 63:157-166. [PubMed: 18347795]

3. Altmann, K-H.; Schinzer, D. Chemistry and Biology of Epothilones. In: Hanessian, S., editor. Natural Products in Medicinal Chemistry. Wiley-VCH Verlag GmbH \& Co KGaA; Weinheim, Germany: 2014. p. 83-125.

4. (a) Klar U, Buchmann B, Schwede W, Skuballa W, Hoffmann J, Lichtner RB. Angew Chem Int Ed. 2006; 45:7942-7948.(b) Krause W, Klar U. Curr Cancer Ther Rev. 2011; 7:10-36.(c) Klar U, Plaatzek J. Synlett. 2012; 23:1291-1299.

5. Chou TC, Zhang X, Zhong ZY, Li Y, Feng L, Eng S, Myles DR, Johnson R, Wu N, Yin YI, Wilson RM, Danishefsky SJ. Proc Natl Acad Sci U S A. 2008; 105:13157-13162. [PubMed: 18755900]

6.

For reviews on the total synthesis of the epothilones, see ref. 3 and:

(a) Harris CR, Danishefsky SJ. J Org Chem. 1999; 64:8434-8456.(b) Nicolaou KC, Roschangar F, Vourloumis D. Angew Chem Int Ed Engl. 1998; 37:2014-2045.(c) Mulzer J. Monatsh Chem. 2000; 131:205-238.(d) Nicolaou KC, Ritzén A, Namoto K. Chem Commun. 2001:1523-1535.(e) Altmann K-H. Org Biomol Chem. 2004; 2:2137-2152. [PubMed: 15280945] (f) Watkins EB, Chittiboyina AG, Avery MA. Eur J Org Chem. 2006:4071-4084.(g) Altmann K-H, Pfeiffer B, Arseniyadis S, Pratt BS, Nicolaou KC. ChemMedChem. 2007; 2:396-423. [PubMed: 17340668] (h) Mulzer J, Altmann KH, Hofle G, Muller R, Prantz K. C R Chimie. 2008; 11:1336-1368.

7.

For more recent syntheses not covered in the reviews in ref. 6, see:

(a) Keck GE, Giles RL, Cee VJ, Wager CA, Yu T, Kraft MB. J Org Chem. 2008; 73:9675-9691. [PubMed: 18991385] (b) Hurski AL, Kulinkovich OG. Tetrahedron Lett. 2010; 51:3497-3500.(c) Wang J, Sun BF, Cui K, Lin GQ. Org Lett. 2012; 14:6354-6357. [PubMed: 23214997] (d) Wang C, Yu M, Kyle AF, Jakubec P, Dixon DJ, Schrock RR, Hoveyda AH. Chem Eur J. 2013; 19:27262740. [PubMed: 23345004] (e) Wessjohann LA, Scheid GO, Eichelberger U, Umbreen S. J Org Chem. 2013; 78:10588-10595. [PubMed: 24079664]

8. Spletstoser JT, Zacuto MJ, Leighton JL. Org Lett. 2008; 10:5593-5596. [PubMed: 19007175]

9. Harrison TJ, Rabbat PMA, Leighton JL. Org Lett. 2012; 14:4890-4893. [PubMed: 22950417]

10. Kitamura M, Ohkuma T, Inoue S, Sayo N, Kumobayashi H, Akutagawa S, Ohta T, Takaya H, Noyori R. J Am Chem Soc. 1988; 110:629-631.

11. Zhao H, Engers DW, Morales CL, Pagenkopf BL. Tetrahedron. 2007; 63:8774-8780.

12. Foley CN, Leighton JL. Org Lett. 2014; 16:1180-1183. [PubMed: 24502345]

13. Kim H, Ho S, Leighton JL. J Am Chem Soc. 2011; 133:6517-6520. [PubMed: 21486033]

14. Leighton JL, Chapman E. J Am Chem Soc. 1997; 119:12416-12417.

15. Hackman BM, Lombardi PJ, Leighton JL. Org Lett. 2004; 6:4375-4377. [PubMed: 15524487]

16. Hale MR, Hoveyda AH. J Org Chem. 1992; 57:1643-1645.

17. Tamao K, Hayashi T, Ito Y. Tetrahedron Lett. 1989; 30:6533-6536.

18.

These conditions were also applied to substrate 13 without success. 

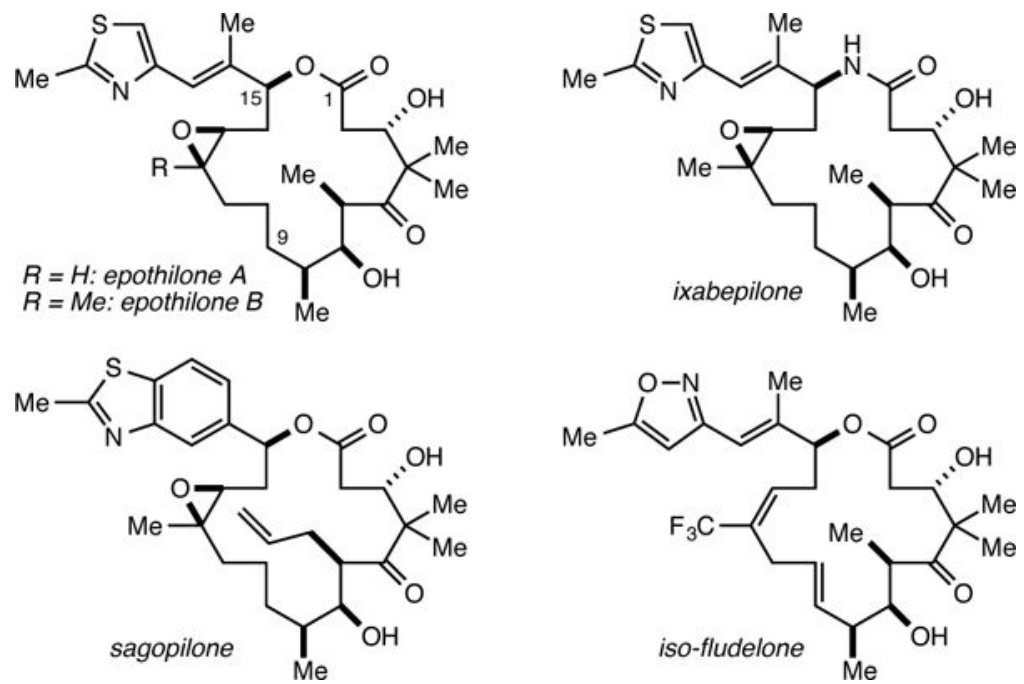

Figure 1.

Epothilones A and B, FDA-approved ixabepilone, sagopilone, and iso-fludelone. 

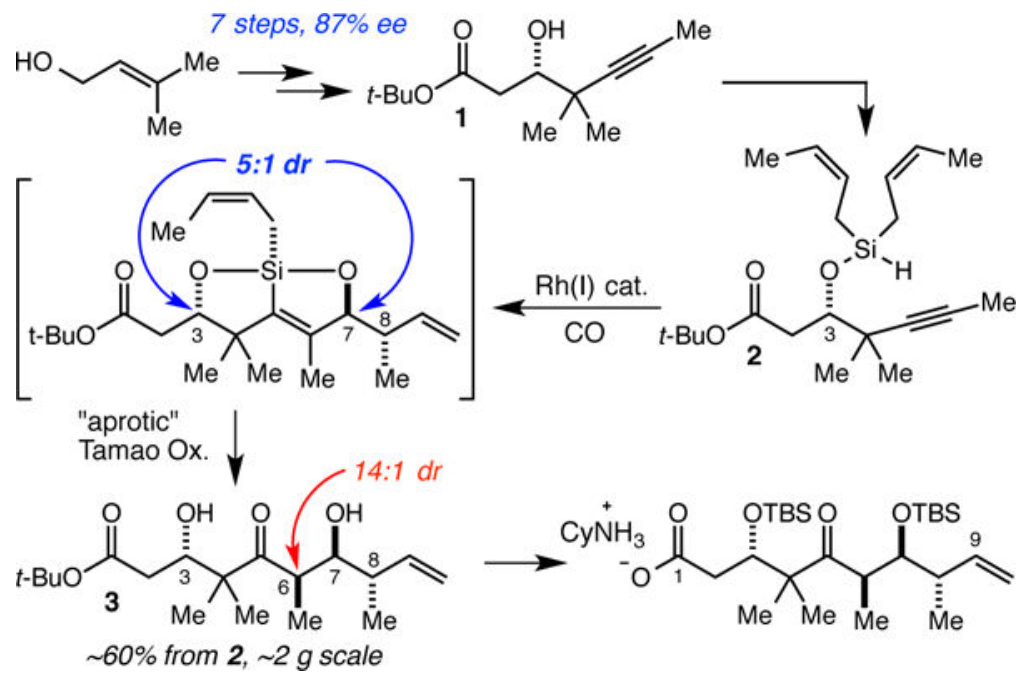

Figure 2.

Our first-generation synthesis of the $\mathrm{C}(1)-\mathrm{C}(9)$ fragment of the epothilones relied on the development of a highly diastereoselective "aprotic" Tamao oxidation/tautomerization reaction. 


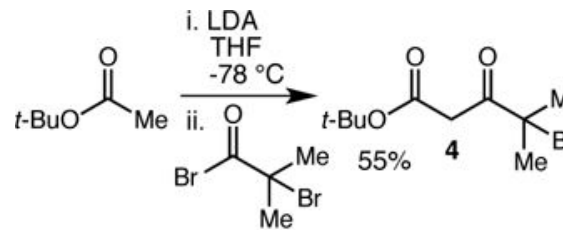

$4 \mathrm{~mol} \%$

(R)-BINAP-

$\mathrm{RuCl}_{2}$
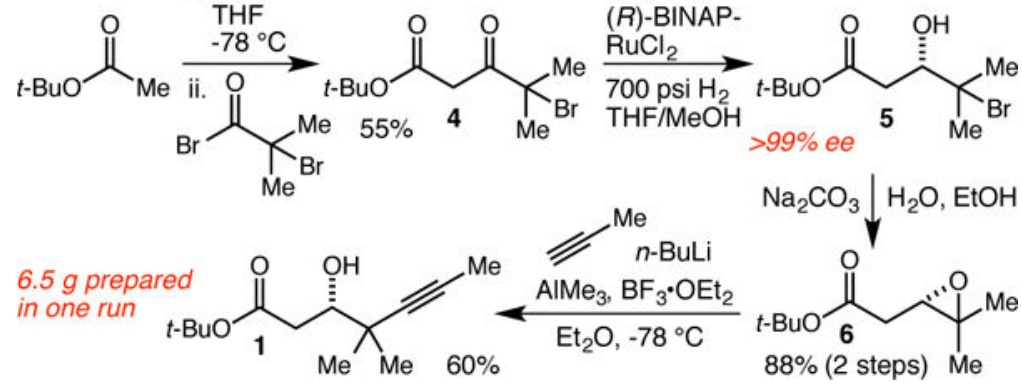

Scheme 1.

An efficient, scalable, and highly enantioselective synthesis of homopropargylic alcohol 1. 

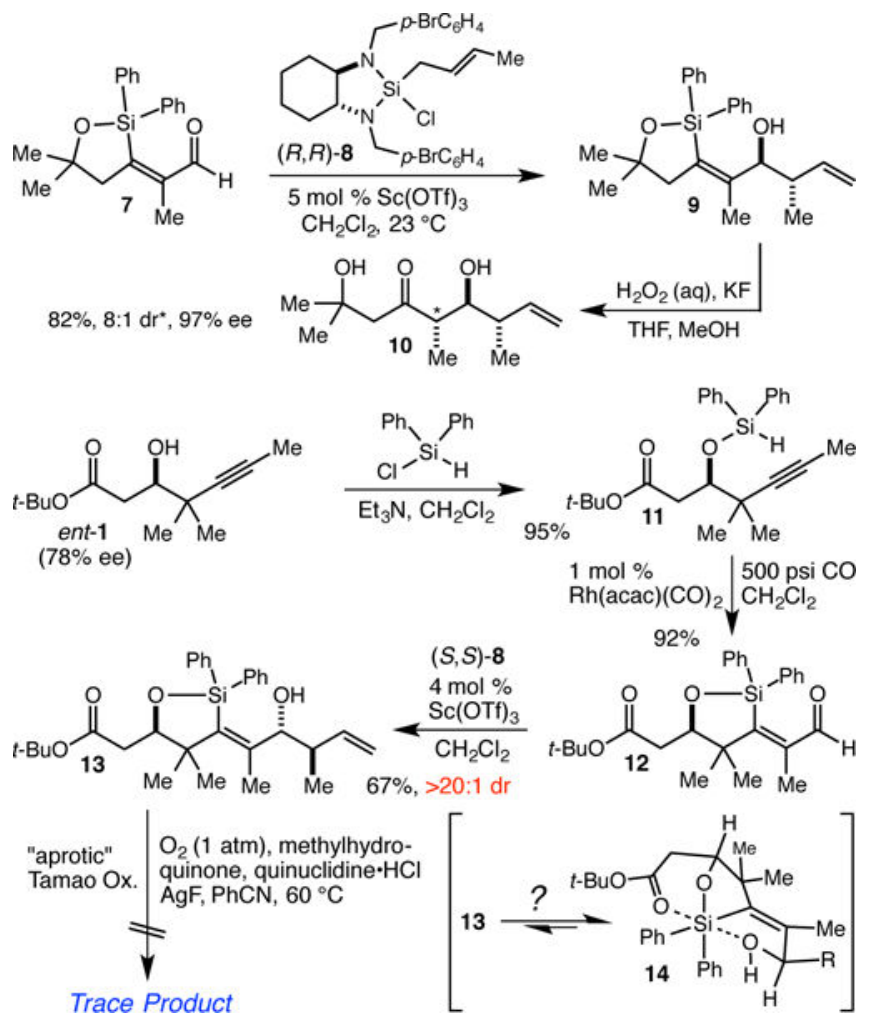

Scheme 2.

Exploration of the stepwise silylformylation/crotylation/oxidation sequence. 

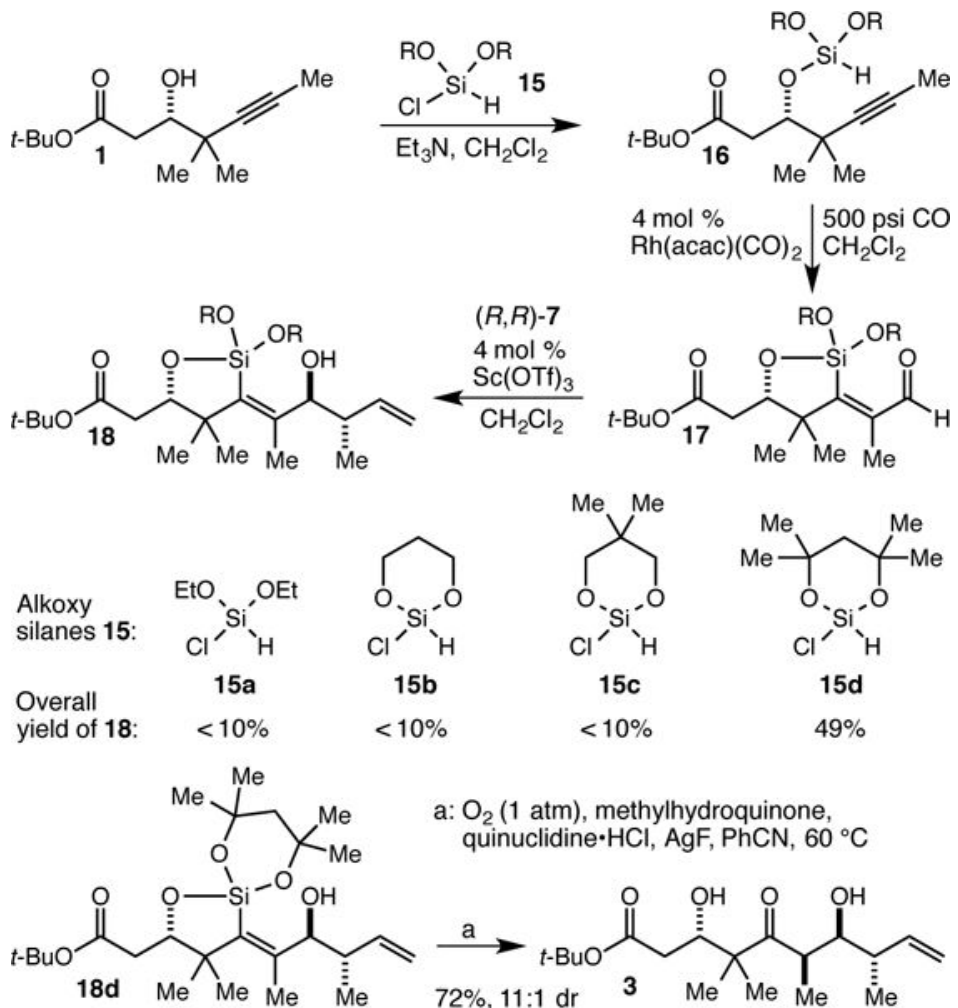<smiles>OCCCO[SiH2]Cl</smiles><smiles>C[Si]1OCC(C)(C)CO1</smiles><smiles>[SiH2][SiH2]</smiles>

$15 \mathrm{c}$<smiles>CC1(C)CC(C)(C)O[SiH](Cl)O1</smiles>

$5 b$

$<10 \%$

$<10 \%$

15d

$49 \%$

a: $\mathrm{O}_{2}$ (1 atm), methylhydroquinone, quinuclidine $\cdot \mathrm{HCl}, \mathrm{AgF}, \mathrm{PhCN}, 60^{\circ} \mathrm{C}$

Scheme 3.

The silylformylation/crotylation/oxidation sequence with alkoxysilanes 15 . 

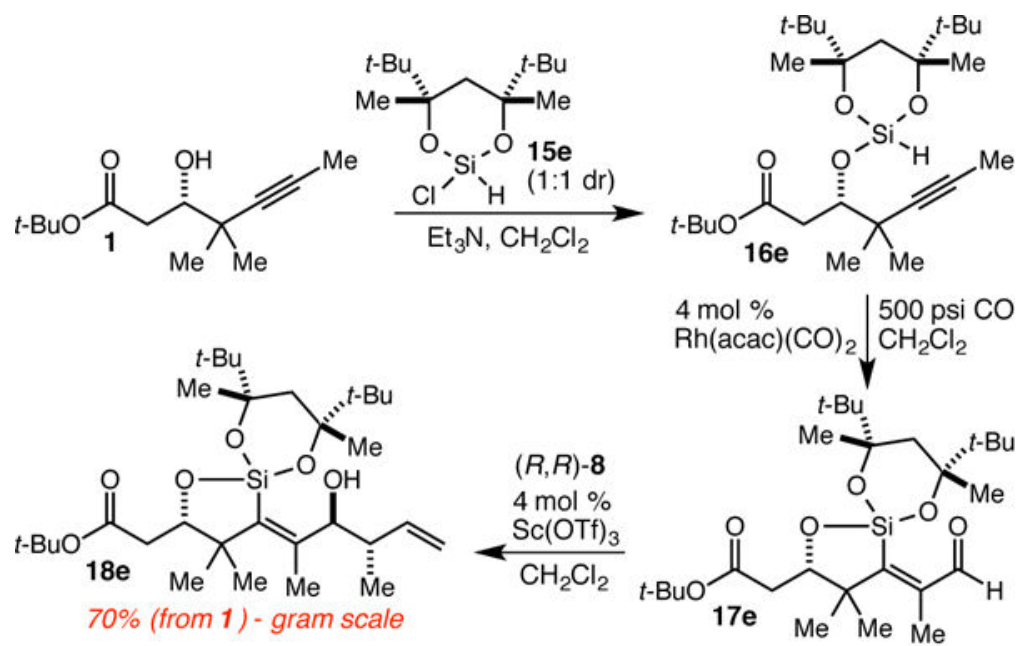

$\mathrm{O}_{2}(1 \mathrm{~atm}) \quad$ quinuclidine $\cdot \mathrm{HCl}$ 2,3-dimethyl- $\mathrm{AgF}, \mathrm{PhCN}, 60^{\circ} \mathrm{C}$ hydroquinone $71 \%, 9: 1 \mathrm{dr}$

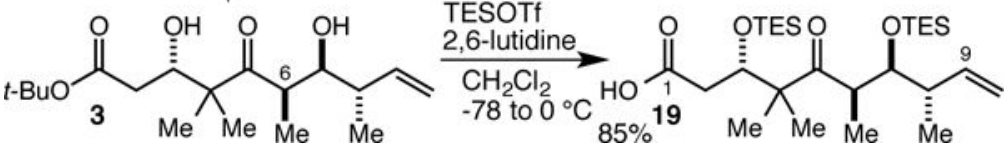

Scheme 4.

An efficient and scalable synthesis of the $\mathrm{C}(1)-\mathrm{C}(9)$ fragment of the epothilones. 